\title{
THE THINGS THEY CARRY: CHARACTERIZING THE BIGGEST PROBLEMS IN THE LIVES OF EMERGING ADULTS
}

\author{
REBECCA J. NORTH \\ The University of Texas at Austin \\ DAVID M. G. LEWIS \\ Bilkent University, Ankara, Turkey \\ MARIA R. CAPECELATRO, BRITTANY N. SHERRILL, SCOTT G. RAVYTS, \\ AND GABRIEL FONTAN* \\ The University of Texas at Austin
}

Drawing on the writings of 315 undergraduate participants who wrote for four consecutive days, 20 minutes each day, about the biggest problem in their lives (North, Pai, Hixon, \& Holahan, 2011), the present study analyzes the text of the writings to characterize the biggest problems in the lives of emerging adults. Specifically, we used two analytic strategies - content coding by raters and linguistic analysis - to address four questions: (1) what were the biggest problems in participants' lives?; (2) were there gender differences in the types of problems that men and women reported?; (3) what was the relative level of emotional distress between individuals with different types of problems?; and (4) were there gender differences in the level of emotional distress associated with the biggest problem in individuals' lives? Findings confirm some existing ideas about major problems facing emerging adults and spotlight new ideas. Findings also challenge longstanding assumptions about gender differences.

Keywords: stressors, emerging adulthood, gender differences, health promotion, relationships

\footnotetext{
*Affiliated with The University of Texas at Austin at the time the research was completed.

Address correspondence to Rebecca J. North, The University of Texas at Austin, Department of Psychology, 1 University Station A8000, Austin, TX 78712; E-mail: rebeccajnorth@austin.utexas.edu
} 
In The Things They Carried, a book of short stories about an American platoon's experience in the Vietnam War, author Tim O'Brien (1990), wrote about the tangible items soldiers carried, like flak jackets, weapons, canteens of water, dog tags, cigarettes, letters from girls, photographs, and each other. He also described what soldiers carried inside: grief, terror, fear of being a coward, the weight of shameful memories, and an instinct to run or hide. These were unseen but felt acutely: "These were intangibles, but the intangibles had their own mass and specific gravity, they had tangible weight" (p. 20). Although only a minority of us has had the experience of being in war-a reality unfathomable to those of us who have not-we all carry invisible burdens. Uncovering those burdens- the biggest problems in people's lives-and identifying what types are most prevalent and most distressing-is the aim of this study.

Numerous studies have demonstrated a relationship between burdens, or stressors, such as negative life events, and increased susceptibility to physical and mental health problems (e.g., Fagan, Galea, Ahern, Bonner \& Vlahov, 2003; Ingram \& Luxton, 2005). Examining the prevalence and emotional impact of stressors could enhance understanding of illness prevention and health promotion (Foster, Hagan, \& Brooks-Gunn, 2008). Moreover, the onset of many mental disorders, such as major depression, bipolar disorder, and substance abuse/dependence occurs between 18 and 24 years of age (Burke, Burke, Regier, \& Rae, 1990; Kessler et al., 2012). Therefore, examining the nature of major stressors among individuals at this critical life stage-emerging adulthood-could make a particularly important contribution.

\section{THE BIGGEST PROBLEMS IN EMERGING ADULTS' LIVES}

Although some research exists on the most prevalent stressors among emerging adults, like college undergraduates, overall, there is a relative dearth of research on this topic. Within the extant body of research, most studies have focused on particular types of stressors, such as past trauma (Pennebaker, Kiecolt-Glaser, \& Glaser, 1988; Romana Alparone, Pagliaro, \& Rizzo, 2015), chronic stressors (Riley \& Park, 2014), daily stressors (LoSavio et al., 2011) or hassles (McIntyre, Korn, \& Matsuo, 2008), problems 
related specifically to coming to college (Pennebaker, Colder, \& Sharp, 1990), or the most stressful academic and social situations (Archer \& Lamnin, 1985). Some of these studies narrowed the scope of stressors even further. For example, in a study involving undergraduate students writing about stressors associated with coming to college, researchers suggested potentially distressing aspects (e.g., leaving your friends or parents) in the writing instructions (Pennebaker et al., 1990). Raters also coded the stressors using a pre-established list (e.g., general academic worries). Despite the use of restricted categories, results from this study provide a solid foundation for understanding major stressors among undergraduates; results indicated that the five most common stressors related to coming to college were: isolation/loneliness, family loss, friend loss, general future worries, and general academic worries. Taken together, the use of restricted categories in previous research limits understanding of what emerging adults deem to be the biggest problems in their lives.

\section{EMOTIONAL DISTRESS}

Moreover, no research that we are aware of investigates the emotional distress associated with different types of stressors. Related research has examined the emotional distress associated with belonging to certain minority groups, such as the LGBT community (Rosario, Schrimshaw, Hunter, \& Gwadz, 2002), immigrants (Yan \& Berliner, 2011), and brain tumor patients (Pelletier, Verhoef, Khatri, \& Hagen, 2002). However, because the stressor in these studies is constant-group membership-these studies do not shed light on comparative levels of distress individuals experience in response to different stressors. Further, because they involve specific populations, they do not address the experience of emerging adults on the whole.

\section{GENDER DIFFERENCES}

There also is a scarcity of research on gender differences in types of major life problems. Existing evidence indicates that men report more work-related problems than women (Matud, 2004), and women report more stressors relating to family and other 
social relationships than men (Brougham, Zail, Mendoza, \& Miller, 2009; Matud, 2004).

Little research also exists on gender differences in emotional distress associated with major life problems, though previous research provides some evidence of a gender difference in overall emotional distress, with women experiencing higher levels of stress than men (Brougham et al., 2009; Matud, 2004; McIntyre, Korn, \& Matsuo, 2008).

\section{PRESENT STUDY}

Drawing on the writings of 315 undergraduate participants who wrote for four consecutive days, 20 minutes each day, about the biggest problem in their lives, the present study seeks to address limitations of previous research by examining emerging adults' biggest life problems, comparing levels of emotional distress associated with distinct types of problems, and investigating gender differences in types of problems and emotional distress. Specifically, we analyzed the writings to address four overarching questions: (1) what were the biggest problems in participants' lives?; (2) were there gender differences in the types of problems that men and women reported?; (3) what was the relative level of emotional distress between individuals with different types of problems?; and (4) were there gender differences in the level of emotional distress associated with the biggest problem in individuals' lives?

\section{METHOD}

\section{PARTICIPANTS}

Three hundred and fifteen undergraduate students (205 women, 110 men) at the University of Texas at Austin participated in an expressive writing study. Participants received either course credit for an Introduction to Psychology class or a chance to win a raffle. 


\section{BACKGROUND ON WRITING SAMPLES}

Writing samples for the present study come from an expressive writing experiment that tested the relative impact of three emotion regulation strategies on emotional well-being (see North et al., 2011). Participants were randomly assigned to one of three conditions: (1) emotional disclosure (i.e., standard expressive writing paradigm; Pennebaker, 1997), (2) positive reappraisal (Gross \& John, 2003), or (3) acceptance + positive reappraisal, a novel emotion regulation strategy integrating these two established strategies. Results demonstrated that the strategy integrating acceptance and positive reappraisal led to better emotional well-being outcomes at post-intervention, controlling for pre-intervention. A subsequent study based on writings from this experiment investigated changes in language use (e.g., use of firstperson pronouns) across the four days of writing to gain further insight into psychological changes that may have occurred (e.g., changes in attentional focus) over the course of writing (North, Meyerson, Brown, \& Holahan, 2012).

\section{PROCEDURE}

For the present study, we analyzed the content of the writings by using two methods: (1) content coding by raters and (2) linguistic analysis of content words using Linguistic Inquiry and Word Count (Pennebaker, Booth, \& Francis, 2007a; Pennebaker, Booth, \& Francis, 2007b).

Content Coding. We used an inductive approach to code problems described in the writings. First, the first and second authors read all participant writings independently. Since some participants' writings included more than one topic, we established criteria to determine what constituted a problem; a topic was classified as a problem if it was a stand-alone issue (i.e., not part of another problem) and appeared to cause a similar amount of distress as the other articulated problem(s). On average, participants wrote about 1.7 problems $(S D=.88$; Range: $1-5$; Mode and 
Median =1). The first and second authors independently labeled the problems using short phrases or single words (e.g., uncertain of ability to be successful in post-college life; unrequited loveintense feelings of jealousy for people who spend time with this person; loneliness as a consequence of language barrier; eating disorder). Next, the two lists were compared, and discrepancies were discussed and reconciled to create one comprehensive list.

Then, problems were organized into categories to capture broader themes. This procedure resulted in twenty-seven categories. For example, the problem "loneliness as a consequence of language barrier" was assigned to a loneliness category with other problems relating to loneliness. "Eating disorder" was placed in a health and well-being category. A separate category called other's health and well-being was created for problems that related to the health and well-being of someone other than the participant (e.g., family or friend). In addition, a category miscellaneous was created to capture problems that did not fit into any category (e.g., lacking mentor-type figure), and for the few individuals who did not specify what the problem was that they were writing about, we created a not otherwise specified category (e.g., unclear-grappling with some type of pain but didn't specify). Consider this sample of categories with examples of raters' descriptions of participants' problems.

Academic (unsure of self in more academically-challenging college environment)

Romantic relationships (lost, lonely, and depressed after break-up with girlfriend)

Family (fear of disappointing parents)

Uncertainty about the future (scared about the future)

Fear of failure (feels like a failure for not doing well in school and fears being a failure in life)

Weight (feels fat and unattractive because of recent weight gain) 
Seven categories were multi-dimensional and therefore could be further categorized, so we created sub-categories. For example, we identified six sub-categories within Romantic Relationships: Being single, Unrequited love, Sex, Jealousy/insecurity, Doubt, and Break-up. For the Family category, seven sub-categories emerged: Homesickness/loneliness related to being away from family and home, Conflict, Pressure from parents, Fear of disappointing parents, Emotional neglect, Independence, Divorce. (See Table 1 for a list of all categories and sub-categories.)

To test the reliability of the first and second authors' coding, a third, independent rater coded a subset of the writings $(n=$ 100 participants) using the same scheme. She was provided a description of the 27 categories, including the types of problems in each category, and received instruction about criteria for what constituted a separate problem. She identified the number of problems that each participant wrote about and assigned each problem to one of the 27 established categories. The correlation between her coding and that of the first and second author was based on the match between the number of problems identified per participant, as well as the match of the categories themselves $(r=0.50)$. (The formula for calculating correlation coefficients with nominal data can be found in Pelham, 2012.)

Linguistic Analysis. To investigate the research questions further, we used a second method: linguistic analysis. We analyzed the writings by using LIWC, 2007. LIWC is a linguistic analysis tool that has been validated in many studies (e.g., Pennebaker, Mehl, \& Niederhoffer, 2003); it categorizes words into approximately eighty categories, including conventional language categories (e.g., articles, pronouns), psychological processes (e.g. cognitive processes and emotion words), relativity-related words (e.g., verb tense, time), and traditional content categories (e.g., work, family, death, sex; Pennebaker et al., 2003). LIWC reports results for each category as a percentage of total words. For this study, we used LIWC categories that related to the content of writings (e.g., family and work words). Because linguistic analysis offers a means to address similar questions in a different way than content coding analysis, it provides an opportunity to corroborate findings based on the inductive content coding process. 
TABLE 1. Percent of Total Individuals with Major Problems in Each Category (in Bold) and Sub-Category

\begin{tabular}{|c|c|c|}
\hline \multirow{2}{*}{$\begin{array}{l}\text { Categories and Sub-Categories } \\
\text { Academic }\end{array}$} & \multicolumn{2}{|c|}{ \% Group Membership } \\
\hline & & $40 \%$ \\
\hline Grades & 12 & \\
\hline Stress & 7 & \\
\hline Time Management & 7 & \\
\hline Lack of Focus & 6 & \\
\hline Failure (objectively defined) & 4 & \\
\hline Class & 4 & \\
\hline Major & 3 & \\
\hline Miscellaneous & 1 & \\
\hline Transfer & .3 & \\
\hline Test Anxiety & .3 & \\
\hline Romantic Relationships & & $23 \%$ \\
\hline Break-Up & 6 & \\
\hline Unrequited Love & 3 & \\
\hline Being Single & 2 & \\
\hline Doubt & 2 & \\
\hline Long-Distance & 2 & \\
\hline Jealousy/Insecurity & 2 & \\
\hline Conflict in Current Relationship & 2 & \\
\hline Not otherwise specified & 1 & \\
\hline Trust & 1 & \\
\hline Unwanted Romantic Advance & 1 & \\
\hline Cheating & 1 & \\
\hline Sex & .6 & \\
\hline Family & & $15 \%$ \\
\hline Loneliness & 5 & \\
\hline Conflict & 4 & \\
\hline Parent Pressure & 3 & \\
\hline Fear of Disappointing Family & 2 & \\
\hline Emotional Neglect & 1 & \\
\hline Independence & 1 & \\
\hline Divorce & .3 & \\
\hline Uncertainty about Future & & $9 \%$ \\
\hline Health and Well-Being & & $8 \%$ \\
\hline Mental & 5 & \\
\hline Physical & 3 & \\
\hline Alcohol/Drugs & .6 & \\
\hline Legal & 0 & \\
\hline Not otherwise specified & 0 & \\
\hline
\end{tabular}


TABLE 1. (continued)

\begin{tabular}{|c|c|c|}
\hline \multirow{2}{*}{$\begin{array}{l}\text { Categories and Sub-Categories } \\
\text { Friends }\end{array}$} & \multicolumn{2}{|c|}{$\%$ Group Membership } \\
\hline & & $8 \%$ \\
\hline Making Friends & 4 & \\
\hline Conflict & 2 & \\
\hline Loss & 2 & \\
\hline Not otherwise specified & .3 & \\
\hline Fear of Failure & & $7 \%$ \\
\hline Miscellaneous & & $5 \%$ \\
\hline Other's Health and Well-Being & & $5 \%$ \\
\hline Legal-Family & 1 & \\
\hline Alcohol/Drugs-Family & 1 & \\
\hline Not otherwise specified-Family & 1 & \\
\hline Physical-Family & .6 & \\
\hline Mental-Family & .3 & \\
\hline Physical-Friend & .3 & \\
\hline Mental-Friend & .3 & \\
\hline Legal-Friend & .3 & \\
\hline Alcohol/Drugs-Friend & 0 & \\
\hline Not otherwise specified-Friend & 0 & \\
\hline Loneliness & & $4 \%$ \\
\hline Low Self-Esteem & & $4 \%$ \\
\hline Lack of Balance & & $4 \%$ \\
\hline Roommate & & $4 \%$ \\
\hline Money & & $4 \%$ \\
\hline Weight & & $3 \%$ \\
\hline Identity & & $3 \%$ \\
\hline Abuse/Trauma & & $3 \%$ \\
\hline Adjusting to College & & $2 \%$ \\
\hline \multicolumn{3}{|l|}{ Independence } \\
\hline Death & & $2 \%$ \\
\hline Relative & 1 & \\
\hline Friend & .3 & \\
\hline Pet & .3 & \\
\hline Sleep & & $2 \%$ \\
\hline Religion & & $2 \%$ \\
\hline Sexuality & & $1 \%$ \\
\hline Guilt & & $1 \%$ \\
\hline Citizenship/Immigration & & $1 \%$ \\
\hline Pregnancy & & $1 \%$ \\
\hline Not Specified & & $1 \%$ \\
\hline
\end{tabular}




\section{MEASURES}

Emotional Distress. Emotional distress associated with each participant's focal problem was assessed using a $0-10$ scale $(0=$ no emotional distress; 10 = extremely significant emotional distress; see North et al., 2011, for details).

Language Categories. LIWC category variables were used to represent the three most common categories of participant problems from raters' coding: academic (represented by the LIWC category Work), romantic relationships (represented by the LIWC category Sexual), and family (represented by the LIWC category Family). In other words, these corresponding LIWC variables served as proxies for the corresponding content-coding categories. The LIWC category Work consists of words relating to work (e.g., work, majors, class). The LIWC category Sexual includes words like love, kiss, and sex. The LIWC category Family includes words like daughter, father, and aunt.

\section{ANALYSES}

\section{WHAT WERE THE BIGGEST PROBLEMS IN} PARTICIPANTS' LIVES?

Content Coding. Percentages were calculated for group membership to each content-coding category (e.g., academic: no $=0$, yes $=1$ ) to determine the most prevalent types of problems. In addition, percentages were calculated for group membership to each sub-category (e.g., grades, within academic category) to determine the most prevalent sub-categories.

Linguistic Analysis. A one-way Analysis of Variance (ANOVA) was conducted with each of the top three content-coding categories as factors (i.e., academic, romantic relationships, and family) and corresponding LIWC variables as outcomes (i.e., work, sexual, and family) to assess whether participants who had a family-related problem, for example, used more family words. 


\section{WERE THERE GENDER DIFFERENCES IN THE TYPES OF PROBLEMS THAT MEN AND WOMEN REPORTED?}

Content Coding. Chi-squared tests were conducted to examine whether there was a significant relationship between gender and content-coding category for the three most common categories: academic, romantic relationships, and family.

Linguistic Analysis. To further investigate gender differences in participants' most common problems, three separate ANOVAs were conducted with gender as the factor and corresponding LIWC categories work, sexual, and family as outcomes.

WHAT WAS THE RELATIVE LEVEL OF EMOTIONAL DISTRESS ASSOCIATED WITH SPECIFIC TYPES OF PROBLEMS?

Content Coding. To examine the level of emotional distress of participants experiencing different types of problems, ANOVAs were conducted with group membership to content-coding categories $(0=$ no; $1=$ yes $)$ as factors and emotional distress as the outcome.

WERE THERE GENDER DIFFERENCES IN THE OVERALL LEVEL OF EMOTIONAL DISTRESS?

Finally, gender differences in overall emotional distress were examined by conducting an ANOVA with gender as the factor and emotional distress as the outcome.

\section{RESULTS}

WHAT WERE THE BIGGEST PROBLEMS IN PARTICIPANTS' LIVES?

Content Coding. The most prevalent categories of problems were: (1) Academic: 40\%, (2) Romantic relationships: 23\%, (3) Family: $15 \%$, (4) Uncertainty about the future: 9\%, (5) Health and well-being: $8 \%$, (6) Friends: $8 \%$, and (7) Fear of failure: 7\%. Other 
TABLE 2. Means and Standard Deviations for LIWC Word Variables (Percentage of Total Word Use)—Work, Sexual, and Family_Within Corresponding Content-Coding Categories-Academic, Romantic Relationships, Family-as Compared to Others

\begin{tabular}{lccccc}
\hline LIWC Variables & \multicolumn{2}{c}{ Within Corresponding Category } & & \multicolumn{2}{c}{ Not Within Corresponding Category } \\
\cline { 2 - 3 } \cline { 5 - 6 } & Mean & $S D$ & & Mean & SD \\
\hline Work & 4.63 & 2.15 & & 2.41 & 1.68 \\
Sexual & 0.34 & 0.35 & & 0.21 & 0.29 \\
Family & 1.41 & 1.28 & & 0.50 & 0.67 \\
\hline
\end{tabular}

Note: Corresponding content-coding category for LIWC variable Work is Academic; for Sexual is Romantic relationships; for Family is Family.

categories consisted of $5 \%$ or less of the participant sample. (See Table 1 for percentages for each category.)

Among the top seven categories, two were uni-dimensional and therefore had no sub-categories: Uncertainty about the future and fear of failure. The other five-Academic, Romantic relationships, Family, Health and well-being, and Friends-were multi-dimensional and therefore had sub-categories. For Academic, the top sub-category was Grades (12\%); two sub-categories tied for second with $7 \%$ each: stress (related to school) and Time management. (Percentages are based on entire participant sample.) The two most common sub-categories for Romantic relationships were Break-ups (6\%) and Unrequited love (3\%). For Family, the top two sub-categories were Loneliness (specific to being away from family and home) (5\%) and Conflict (4\%). For Health and well-being, the top two sub-categories were Mental health $(5 \%)$ and Physical health (3\%) of the participant. Finally, for Friends, the two most common sub-categories were Making friends $(4 \%)$ and Conflict (2\%). (See Table 1 for percentages of each sub-category.)

Linguistic Analysis. All three ANOVAs revealed that participants who had a major problem in the specified content-coding category used significantly more words related to that category than other participants, offering converging evidence for the content coding scheme. Specifically, ANOVA results for group membership to Academic category and LIWC Work words were significant: $F(1,313)=105.07, p<.001$, as were results for the Romantic relationships category and Sexual words $F(1,313)=$ 
$10.22, p<.01$, and Family category and Family words $F(1,313)=$ $53.13, p<.001$. (See Table 2 for means and standard deviations.)

\section{WERE THERE GENDER DIFFERENCES IN THE BIGGEST PROBLEMS IN UNDERGRADUATES' LIVES?}

Content Coding. A chi-squared analysis revealed a significant relationship between gender and family problems $\left(\chi^{2}=6.516, p\right.$ $=.011$ ), such that women were more likely to have Family as a major problem in their lives than men $($ Women $=19 \%$; Men $=$ $8 \%$ ). Of note are findings indicating no significant relationship between gender and academic problems $\left(\chi^{2}=2.353, p>.05\right)$ or gender and Romantic relationship problems $\left(\chi^{2}=3.693, p>.05\right)$.

Linguistic Analysis. A one-way ANOVA revealed that the relationship between gender and Family words was significant: $(F(1,313)=6.99, p=.009)$; women used more words related to Family (Mean $=.73 ; S D=.94)$ than males (Mean $=.47 ; S D=0.63$ ). Also, a one-way ANOVA indicated no significant relationship between gender and use of "sexual" words, $F(1,313)=.011, p=$ $>.05$. Results did indicate a significant relationship between gender and Work words: $F(1,313)=5.176, p=.024$; men used more words related to Work (Mean $=3.67 ; S D=2.33$ ) than women (Mean $=3.09 ; S D=2.05)$.

\section{WHAT WAS THE RELATIVE LEVEL OF EMOTIONAL DISTRESS ASSOCIATED WITH SPECIFIC TYPES OF PROBLEMS?}

First, overall, the average level of emotional distress associated with the biggest problem in participants' lives was $5.42(S D=$ 1.85; minimum $=1 ;$ maximum $=9.5 ; N=314$ - one missing score for emotional distress).

Content Coding. ANOVA results were significant for the relationship between the category Death and emotional distress, $F(1,312)=15.35, p<.001$; participants whose major problems re- 
lated to Death had the highest mean of emotional distress (Mean $=8.29, S D=.93)$, significantly higher than participants with no major problems in this area (Mean $=5.36 ; S D=1.82$ ). ANOVA results also revealed a significant relationship between the category Abuse and trauma and Emotional distress $F(1,312)=9.685, p=$ .002 , indicating that participants whose major problems related to Abuse and trauma experienced greater emotional distress $($ Mean $=7.40 ; S D=2.07)$ than others $($ Mean $=5.37 ; S D=1.82)$. Further, there was a significant relationship between other's health and well-being and emotional distress, $F(1,312)=4.526$, $p=.03$, whereby participants with major problems relating to other's health and well-being had significantly higher emotional distress $($ Mean $=6.38, S D=1.67)$ than others $($ Mean $=5.37 ; S D=$ 1.85). Finally, ANOVA results were significant between Academic category and emotional distress, $F(1,312)=15.88, p<.001$, but in the opposite direction; participants who had a major problem in the Academic category experienced lower emotional distress (Mean $=4.92 ; S D=1.82)$ than those whose major problem was not academic $($ Mean $=5.75 ; S D=1.81)$.

\section{WERE THERE GENDER DIFFERENCES IN THE OVERALL LEVEL OF EMOTIONAL DISTRESS?}

ANOVA results were not significant for the relationship between gender and emotional distress, $F(1,312)=1.270, p>.05$, indicating equivalent levels of emotional distress for females $($ Mean $=$ $5.51 ; S D=1.93)$ and males $($ Mean $=5.26 ; S D=1.71)$.

\section{DISCUSSION}

The present study aimed to uncover the biggest problems in the lives of emerging adults, identifying what types are most prevalent and most distressing, and to investigate possible gender differences. The results offer a fine-grained assessment of the major problems in the lives of emerging adults and contribute, more generally, by addressing overlooked research questions and 
challenging some longstanding assumptions about gender differences.

Results indicate that, consistent with previous research, the most common areas of major life problems among undergraduates include academics, relationships (including romantic, family, and friend), and uncertainty about the future. Present findings reveal two new common categories of major life problems among undergraduates that have not been emphasized in previous research: health and well-being and fear of failure. Present findings also offer a rich, detailed understanding of the nature of undergraduates' biggest problems. For example, major academic problems most frequently related to grades, stress, and time management. Major romantic problems typically related to break-ups and unrequited love. And major problems in the domain of health and well-being most frequently related to one's mental health. Linguistic analysis regarding the biggest problems in undergraduates' lives provided converging evidence for the content coding analysis, further bolstering findings.

Consistent with previous research, women experienced major family-related problems more frequently than men. Diverging from previous research, present findings indicated that there were no gender differences relating to experiencing major life problems in academics or romantic relationships. Men and women were equally likely to have the biggest problems in their lives relate to academics, as well as romantic relationships. These findings challenge longstanding, conventional assumptions that men are more achievement-oriented than women and that women are more likely to experience distress relating to romantic relationships than men. In addition, there were no gender differences in use of Sexual words, further indicating that men and women discussed romantic issues at equivalent rates. However, findings relating to the use of Work words revealed that men used more Work words than women. This finding, taken together with the corresponding content-coding finding, suggests that although men and women experienced major academic-related problems with similar frequency, men wrote at greater length about their work-related problems. 
Findings revealed that academic problems were associated with the least emotional distress; emerging adults who had a major problem in the area of academics experienced less emotional distress than those who did not. In contrast, people whose major life problem was characterized by death, abuse or trauma, or other's health and well-being experienced the highest levels of emotional distress. These findings further understanding about which stressors are likely to tax or Weather people at a psychological level more quickly, leaving them more vulnerable to future mental and physical health problems (Foster et al., 2008).

No gender differences existed in the emotional distress associated with the biggest problem in an individual's life. Although there is scant previous research on this precise topic, related research that does exist indicates that women experience more stress than men. This finding-that the level of emotional distress associated with the biggest problem in one's life was equivalent for men and women-challenges conventional assumptions about the emotional landscapes of men and women and offers a new perspective that ought to be researched further.

Finally, it is worth noting that the biggest problems in undergraduates' lives were quite distressing $(M=5.42 ; S D=1.85)$. Whereas previous research has shown that daily stressors of college students are not very stressful (LoSavio et al., 2011), other research has shown that chronic stressors in undergraduates' lives are quite stressful (Riley \& Park, 2014); findings from this study provide further evidence that undergraduates are contending with distressing problems.

There are limitations to the present study. For example, findings may not generalize to all emerging adults. In fact, they most likely do not apply fully to emerging adults who do not attend college. Also, although analyses allowed for a detailed assessment of problems, an examination with an even finer resolution is possible and would make a meaningful contribution. A more detailed, nuanced analysis would increase understanding of people's biggest life problems and therefore enhance understanding of factors relating to health promotion and illness prevention.

Also, future research following participants over timethrough their transition to college, graduation (or end of college 
experience), and even after graduation-would make a unique, meaningful contribution. Investigating, for example, how the nature of people's biggest life problems change (e.g., do students who report academics as their biggest life problem also report work as their biggest problem later?) and how people's level of emotional distress associated with their biggest life problem changes as they get older, and as problems change, would cast more light on this important area.

\section{REFERENCES}

Archer, J., \& Lamnin, A. (1985). An investigation of personal and academic stressors on college campuses. Journal of College Student Personnel, 26, 210-215.

Brougham, R. R., Zail, C. M., Mendoza, C. M., \& Miller, J. R. (2009). Stress, sex differences, and coping strategies among college students. Current Psychology: A Journal for Diverse Perspectives on Diverse Psychological Issues, 28, 85-97.

Burke, K. C., Burke, J. D., Regier, D. A., \& Rae, D. S. (1990). Age at onset of selected mental disorders in five community populations. Archives of General Psychiatry, 47, 511-518.

Fagan, J., Galea, S., Ahern, J., Bonner, S., \& Vlahov, D. (2003). Relationship of selfreported asthma severity and urgent health care utilization to psychological sequelae of the September 11, 2001 terrorist attacks on the World Trade Center among New York City area residents. Psychosomatic Medicine, 65, 993-996.

Foster, H., Hagan, J., \& Brooks-Gunn, J. (2008). Growing up fast: Stress exposure and subjective 'weathering' in emerging adulthood. Journal of Health and Social Behavior, 49, 162-177.

Gross, J. J., \& John, O. P. (2003). Individual differences in two emotion regulation processes: Implications for affect, relationships, and well-being. Journal of Personality and Social Psychology, 85, 348-362.

Ingram, R. E., \& Luxton, D. D. (2005). Vulnerability-Stress Models. In B. L. Hankin \& J.R.Z. Abela (Eds.), Development of psychopathology: A vulnerability stress perspective (pp. 32-46). Thousand Oaks, CA: Sage.

Kessler, R. C., Avenevoli, S., Costello, E., Georgiades, K., Green, J., Gruber, M. J., \& Merikangas, K. (2012). Prevalence, persistence, and sociodemographic correlates of DSM-IV disorders in the National Comorbidity Survey Replication Adolescent Supplement. Archives of General Psychiatry, 69, 372-380.

LoSavio, S. T., Cohen, L. H., Laurenceau, J.-P., Dasch, K. B., Parrish, B. P., \& Park, C. L. (2011). Reports of stress-related growth from daily negative events. Journal of Social and Clinical Psychology, 30, 760-785.

Matud, M. (2004). Gender differences in stress and coping styles. Personality and Individual Differences, 37, 1401-1415.

McIntyre, K. P., Korn, J. H., \& Matsuo, H. (2008). Sweating the small stuff: How different types of hassles result in the experience of stress. Stress and Health: Journal of the International Society for the Investigation of Stress, 24, 383-392. doi:10.1002/smi.1190. 
North, R. J., Meyerson, R. L., Brown, D. N., \& Holahan, C. J. (2012). The language of psychological change: Decoding an expressive writing paradigm. Journal of Language and Social Psychology, 32, 142-161.

North, R. J., Pai, A. V., Hixon, J. G., \& Holahan, C. J. (2011). Finding happiness in negative emotions: An experimental test of a novel expressive writing paradigm. The Journal of Positive Psychology, 6, 192-203.

O'Brien, T. (1990). The things they carried. New York: Penguin Books.

Pelham, B. W. (2012). Intermediate statistics: A conceptual course. New York: Sage.

Pelletier, G., Verhoef, M. J., Khatri, N., \& Hagen, N. (2002). Quality of life in brain tumor patients: The relative contributions of depression, fatigue, emotional distress, and existential issues. Journal of Neuro-Oncology, 57, 41-49.

Pennebaker, J. W. (1997). Writing about emotional experiences as a therapeutic process. Psychological Science, 8, 162-166.

Pennebaker, J. W., Booth, R. J., \& Francis, M. E. (2007a). Linguistic Inquiry and Word Count: LIWC [Computer software]. Austin, TX: LIWC.net.

Pennebaker, J. W., Booth, R. J., \& Francis, M. E. (2007b). Operator's Manual Linguistic Inquiry and Word Count: LIWC2007. Austin, TX: LIWC.net.

Pennebaker, J. W., Colder, M., \& Sharp, L. K. (1990). Accelerating the coping process. Journal of Personality and Social Psychology, 58, 528-537.

Pennebaker, J. W., Kiecolt-Glaser, J. K., \& Glaser, R. (1988). Disclosure of traumas and immune function: Health implications for psychotherapy. Journal of Consulting and Clinical Psychology, 56, 239-245.

Pennebaker, J., Mehl, M., \& Niederhoffer, K. (2003). Psychological aspects of natural language use: Our words, our selves. Annual Review of Psychology, 54, 547-577.

Riley, K. E., \& Park, C. L. (2014). Problem-focused vs. meaning-focused coping as mediators of the appraisal-adjustment relationship in chronic stressors. Journal of Social and Clinical Psychology, 33, 587-611.

Romana Alparone, F., Pagliaro, S., \& Rizzo, I. (2015). The words to tell their own pain: Linguistic markers of cognitive reappraisal in mediating benefits of expressive writing. Journal of Social and Clinical Psychology, 34, 495-507.

Rosario, M., Schrimshaw, E. W., Hunter, J., \& Gwadz, M. (2002). Gay-related stress and emotional distress among gay, lesbian and bisexual youths: A longitudinal examination. Journal of Consulting and Clinical Psychology, 70, 967-975.

Yan, K., \& Berliner, D. C. (2011). An examination of individual level factors in stress and coping processes: Perspectives of Chinese international students in the United States. Journal of College Student Development, 52, 523-542. 